\title{
A PROBLEMÁTICA DA TEMPERATURA CORPORAL ENQUANTO UM PROCEDIMENTO DE ENFERMAGEM: CONCEITOS E MECANISMOS REGULADORES
}

\author{
Maria Teresa Cicero Laganá $*:$ \\ Ana Cristina Mancussi e Faro* \\ Thelma Leite Araujo*
}

LAGANÁ, M.T.C.; FARO, A.C.M. e; ARAUJO, T.L. A problenática da temperatura corporal, enquanto um procedimento de enfermagem: conceitos e mecanismos regu. ladores. Rev. Esc. Enf. USP, v. 26, n. 2, p. 173-86, Ago. 1992.

$O$ presente estudo mostra a problemática da temperatura corporal enquanto um procedimento de enfermagem. Apresenta conceitas relacionados à temperatura e suas alterações, $e$ descreve duas entidades nosológicas relacionadas com a elevação da temperatura: febre e hipertermia maligna. gulaşão

UNITERMOS: Assistência de enfermagem. Febre. Temperatura corporal. Re-

\section{INTRODUÇÃO}

Todas as formas de vida são limitadas pelas respectivas capacida. des de sobreviver a extremos de temperatura. Em geral, quanto mais complexo o ser, mais severas as limitações. $O$ homem vive apenas alguns graus abaixo de seu ponto mortal, sofrendo variações internas compatíveis com a saúde, associadas intimamente ao ritmo de produ. ção metabólica.

Alterações de temperatura ambiental abaixo de $18^{\circ} \mathrm{C}$ ou maiores que $45^{\circ} \mathrm{C}$, associam-se com dor e lesão tissular. Temperaturas baixas relacionam-se com formação de cristais que lesam membranas celulares e ocasionam desidratação tissular. Temperaturas altas relacionamse com desnaturação de proteínas, sendo os tecidos destruídos pelo calor muito mais rapidamente do que poderiam ser repostos pela atividade metabólica. A manutenção da hemeotermia interna do homem é assegurada por complicados mecanismos que podem alterar-se devido a inúmeros fatores de ordem biológica, emocional e ambiental.

\footnotetext{
* Assistente do Departamento de Enfermagem Médico-Cirúrgica da Escola de Enfermagem da Universidade de sáo Paulo.

** Professora da Faculdade de Enfermagem do Hospital Israelita Albert Einstein.
} 


\section{CONCEITOS}

Reunindo e homogeneizando os principaís conceitos relativos à temperatura corporal ${ }^{5,9,12,13,17,22}$, adotamos as seguintes definições:

Temperatura: é um índice de calor relativo.

Temperatura corporal: é o balanço entre o calor gerado e o perdido pelo corpo humano.

Medida ou verificação da temperatura corporal: é um método de estimativa da temperatura central do corpo. Todo mecanismo de regulação da temperatura diz respeito à temperatura central ou interior e não à temperatura superficial. Esta aumenta ou diminui de acordo com o meio ambiente e é importante no que se refere à capacidade da pele perder calor para o meio ambiente.

Temperatura corporal normal: nenhum nível isolado de temperatura pode ser considerado normal porque pessoas saudáveis, do mesmo sexo, idade e compleição, apresentam variações entre si. Um mesmo indivíduo sofre variações ao longo do dia e em diferentes locais do corpo. Desta forma as pessoas devem ter seu padrão individual de avaliação da temperatura corporal.

A temperatura corporal habitual do adulto assume os valores médios de $\mathrm{T}$.axilar: $36^{4 \circ} \mathrm{C}$; $\mathrm{T}$. oral: $37^{\circ} \mathrm{C}$ e $\mathrm{T}$. retal: $37^{6 \circ} \mathrm{C}$.

Hipertemia: é a temperatura corporal com uma elevação habitual não patológica, a níveis superiores que $37^{5 \circ} \mathrm{C}$ (axilar), geralmente após exercícios físicos ou emoções intensas.

Febre: é a elevação da temperatura corporal acima da habitual e causada por doença. Considerada um dos mais antigos sinais de doença que se conhece.

Hipotermia: é a temperatura corporal com uma variação a níveis inferiores que $35^{\circ} \mathrm{C}$ (axilar). Esta denominação, quando se refere a criança e idosos é interpretada como a incapacidade para manter a temperatura corporal adequada à manutenção das funções biológicas diante de ambientes frios.

Estado febril: é pelo menos uma medida de temperatura (oral, axilar ou retal) acima dos limites habituais de hipertermia do individuo.

Temperatura central do corpo: é um índice do estado do metabo. lismo corporal, controlado pelo termostato hipotalâmico. A artéria pul. monar tem sido o local preferido para medir a temperatura central porque ela representa o "pool" de sangue das regiōes do corpo. O reto tem a temperatura mais elevada em relação às temperaturas oral $\theta$ axilar, considerada mais próxima da temperatura central. $\mathrm{Na}$ verdade, as temperaturas mais próximas da central são a esofageana e a timpânica, medidas por sondas com procedimentos específicos. Há experimentos visando a medida da temperatura central do corpo feitos no estômago e bexiga urinária. 
Ritmo circadiano individual: é produzido por um sistema de marcapasso endógeno modulado por fatores exógenos (iluminação, exercício extenuante, alimentação e temperatura ambiente). Habitualmente os pontos mínimos são no início da manhã e os pontos máximos no final da tarde ou início da noite. Nos indivíduos em jejum e em completo repouso por tempo prolongado o ritmo circadiano desaparece. Do mesmo modo, a gravidez e o ritmo circamensal do ciclo menstrual, alteram o ponto fixo da temperatura nas mulheres.

\section{O FENOMENO DA FEBRE}

A febre ou pirexia é um incremento da temperatura devido a uma resposta do mecanismo de termorregulação a um estímulo de produtos bacterianos, vírus, antígenos não bacterianos e fungos, além de outros fatores de ativação como: liberação de linfocinas, de prostaglandinas e de AMP (mediador hormonal intracelular) ${ }^{22}$.

Estes estímulos ativam a produção do pirogênio endógeno que $\boldsymbol{\theta}$ de natureza protéica e também fator de ativação dos linfócitos. $O$ pirogênio é produzido principalmente pelas células de Kupffer (macrófa. gos teciduais do fígado), monócitos, histiócitos, macrófagos e, em menor quantidade, pelos neutrófilos e eosinófilos; algumas células tumorais também podem sintetizá-1o.

Após duas horas de ativação ${ }^{22}$ ou a partir de minutos ${ }^{5}$, começa a liberação do pirogênio endógeno pelas células produtoras caindo na corrente sanguínea e indo agir nos neurônios termossensitivos da área pré-óptica do hipotálamo anterior.

Anormalidades no cérebro como tumores cerebrais ou hemorragias intracranianas também podem ser estímulos ao descontrole do sistema termorregulador, ocasionando febre.

Existem algumas febres elevadas de início súbito, estimuladas por agentes bacterianos e virais, que merecem atendimento imediato, principalmente em pacientes internados que estão afebris e subitamente apresentam febre. Este quadro pode ser sugestivo de: pneumonia pneumocócica; infecções agudas do aparelho urinário; amigdalite purulenta; infecções de pele; infecções de ferida; algumas viroses (influenza); estafilococcias; septicemias e gastrenterites ${ }^{22}$.

Introdução de material descartável endógeno, soros e sangue no organismo também são fatores de ativação do pirogênio como substân. cias estranhas ao organismo ${ }^{21}$.

A febre é, então, uma entidade nosológica diferente do fenômeno da hipertermia e caracteriza-se como uma síndrome.

3.1. Caracteristicas clínicas das sindromes febris

(1) Fase Fria - é caracterizada por: pele fria; sensação de frio, palidez; contrações musculares (calafrios); piloereção (arrepios); au. mento da frequiência de pulso perifërico (taquicardia); mialgias, artralgias, mal estar geral e adinamia. 


\section{Interpretação}

O termostato hipotalâmico, após estimulação, começa a fazer o ajusie térmico para elevar a temperatura mas esta, nos receptores térmicos do corpo, ainda é a habitual para o indivíduo e, então, ocorre a vasoconstrição para evitar perda de calor. Para o termostato hipotalâmico conseguir elevar a temperatura, ele estimula as contrações musculares e os arrepios para gerarem calor. Quando a temperatura corporal se iguala ao ajuste hipotalâmico (aproximadamente $38^{\circ} \mathrm{C}$ - axilar), o indivíciuo não experimenta mais ar. repios. A presença de calafrios guarda relação com a intensidade da febre e principalmente com a rapidez da elevação térmica, variando de arrepios a tremores intensos.

(2) Fase Quente - é caracterizada por: aumento do padrão respiratório; rubor, calor, pele quente; hipotensão; anorexia, náuseas, vômitos; irritabilidade do sistema nervoso central (fotofobia, cefaléia); desidratação de pele e mucosas particularmente em bebês, crianças pequenas e idosos. Em temperaturas elevadas observa-se desorientação nos ađultos com delírios ou confusão mental e convulsão nas crianças.

\section{Interpretação}

A temperatura corporal está se elevando e o termostato hipotalâmico está se ajustando. Ao estabilizar o ajuste hipotalâmico começa a vasodilatação periférica para a perda de calor, onde o afluxo de sangue para a pele pode chegar a $30 \%$ do débito cardíaco total.

A intermação, que ocorre a uma temperatura de $41-42^{\circ} \mathrm{C}$, ocasiona hemorragias e degeneração celular, principalmente em órgãos vitais, havendo perigo de morte.

(3) Fase Umida, tem como características: sudorese intensa que permite diminuição da temperatura através da evaporação; pele úmida e pastosa, próxima à temperatura habitual; vasodilatação; aumento do risco de desidratação e eventualmente oligúria.

\section{Interpretação}

Nesta fase a vasodilatação cutânea já se completou, possibilitando a irradiação, a condução e a evaporação. A sudorese contribui com metade da perda da evaporação.

Para cada 1 litro de água que se evapora são necessárias 580 calorias que são retiradas do organismo, com o consequiente resfriamento do mesmo. A evaporação da sudorese é a forma mais eficaz que o indivíduo tem de perder calor quando está com temperatura elevada. O suor produzido adere-se à pele com grande desconforto térmico, o paciente sente sede e muito cansaço. 


\subsection{Hipertermia maligna}

A hipertermia maligna é uma síndrome determinada por uma con. dição genética, com maior incidência em crianças do que em adultos e mortalidade em torno de $30 \% 1,14,18$. E uma das mais sérias emergências em anestesiologia, podendo ocorrer desde a indução até a fase de recuperação pós-anestésica, caracterizada por aumento rápido da temperatura corporal (em média $1^{\circ} \mathrm{C}$ a cada $5^{\prime}$ ), chegando a níveis supe riores a $40^{\circ} \mathrm{C}$, hiperpnéia, taquicardia, com ou sem rigidez muscular, hipóxia e cianose de extremidades, ansiedade e medo, hipotensão arterial, hiperemia de face, sudorese, torpor, confusão mental, agitação; finalizando com acidose metabólica, arritmias cardíacas e morte.

$A$ incidência deste tipo de ocorrência varia conforme a idade. Nos casos relacionados no período de 1971 a 1983 , a proporção foi de 1:15.000 em crianças e de 1:50.000 a 1:100.000 em adultos ${ }^{18}$. São poucos os casos relatados na literatura brasileira ${ }^{18}$ mas é importante o enfermeiro conhecer, porque os cuidados de enfermagem devem ser prestados juntamente com a equipe médica e é uma assistência que demanda rápidas tomadas de decisão. O reconhecimento precoce dos sinais é fundamental para assistir ao paciente em tempo hábil. Os cuidados específicos serão apresentados, juntamente com a febre, na segunda parte deste trabalho.

\section{SOBRE A FISIOLOGIA DA TEMPERATURA CORPORAL 9,10,11,12,13,20}

A homeotermia orgânica sofre uma variação fisiológica de $\pm 0,6^{\circ} \mathrm{C}$ tenazmente mantida entre $37^{\circ}-37^{2 \circ} \mathrm{C}$, de modo que uma pessoa sadia e nua, suporta bem variações do meio ambiente entre 13 e $60^{\circ} \mathrm{C}$. A temperatura corporal normal varia com exercícios (atividade muscular) e com extremos da temperatura ambiente.

O ambiente causa distúrbios na perda calórica e o exercício é responsável por distúrbios internos na produção calórica. Eles são os principais desafios ao sistema regulador na manutenção da temperatura corporal nos limites normais. Numa situação de exercício extenuante, a temperatura retal pode ir de $38^{3 \circ} \mathrm{C}$ para $40^{\circ} \mathrm{C}$ e, numa de frio extremo, pode chegar a $36^{6 \circ} \mathrm{C}$.

A regulação da ternperatura corporal é feita pela parte anterior do hipotálamo, na área pré-ótica, e envolve intrincados mecanismos de vários sistemas do organismo a partir de transferências químicas e físicas de calor, a saber: controle fisiológico (neurológico) e o comportamental; equilíbrio entre produção e perda de calor; sistema isolador do corpo; regulação térmica da pele; secreção das glândulas sudoríparas; aclimatação; receptores termossensíveis e sensibilidade térmica; sistema vasomotor.

Estes mecanismos sofrem influência de: idade, exercícios que podem aumentar a temperatura corporal de $0,5^{\circ}$ a $2^{\circ} \mathrm{C}$ e atividade muscular; hormônios; ambiente (temperatura, iluminação, energia solar, 
umidade relativa do ar); sexo; emoção; alimentos, líquidos, fumo; sono; doenças; natureza da febre (remitente, intermitente, recorrente ou séptica); medicamentos (antitérmicos, antiinflamatórios e antiinfecciosos principalmente); postura corporal, pois as temperaturas esofageana, sublingual e retal são mais elevadas com o indivíduo de pé e maís baixas com a posição supina ${ }^{13}$; "stress" e ritmo circadiano individual.

\subsection{Controle fisiológico e controle comportamental}

A regulação da temperatura corporal deriva basicamente de dois mecanismos: o comportamental, envolvendo uso consciente e voluntário e o fisiológico, empregando as respostas involuntárias do organismo, ambos com uma base neural comum - o termostato hipotalâmico - altamente desenvolvida, que tende a manter a temperatura constante.

A detecção da temperatura no corpo se faz pela pele, vísceras e medula espinhal a partir de descargas dos neurônios sensíveis ao calor, existentes na área pré-ótica do hipotálamo, que conciliam temperatura corporal interna, temperatura ambiente e emoções.

\subsection{Equilibrio entre produção e perda de calor}

Este equilíbrio se dá pelo controle do hipotálamo sobre a termogênese (ganho ou produção) e a termólise (perda de calor), e pode ser assim representado:

\section{TERMOGENESE \\ (GANHO OU PRODUÇXO)}

COMBUSTAO DE ALIMENTOS

METABOLIsMo
BASAL $\left\{\begin{array}{l}\text { Respiração/circulação: } 1 / 10 \\ \text { Cérebro e músculos: 4/10 } \\ \text { Vísceras abdominais: } 5 / 10\end{array}\right.$

AUMENTO DO METABOLISMO POR

ATIVIDADE MUSCULAR

CALAFrIOS E PILOERECAOO

TERMOG ENESE $\left\{\begin{array}{l}\text { Sistemas enzimáticos } \\ \text { Reaçøes químicas } \\ \text { Glandulas secretoras } \\ \text { Hormónios } \\ \text { Mediadores químicos }\end{array}\right.$

TEMPERATURA AMBIENTE

IRRADIACAO SOLAR

F'GBRE

FISIOPATOLOGIAS

\section{TERMOLISE}

(PERDA)

RADIACSAO (60 - 65\%)

- O corpo emite e recebe do meio ambiente ondas eletromagnéticas

EVAPORAÇAO (22 - 27\%)

- Perdas insensivels por pele e pulmzes $=600 \mathrm{ml} / \mathrm{dia}$

CONVEOCCAO (15 - 25\%)

- movimentaçáo do ar

- aumenta com o corpo úmido

CONDUÇÃO (3 - 30\%)

- para objeto, autolimitada: $3 \%$

- em superficie úmida ou em

água: aumenta em $30 \%$

SUDORESE

MEIO AMBIENTE

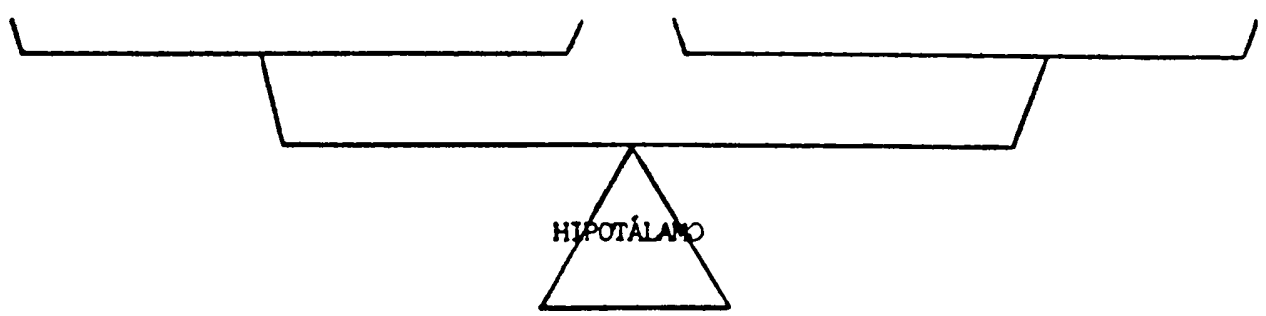




\subsection{O sistema isolador do corpo}

Este sistema, constituído pela pele, tecidos subcutâneos e gordura, possibilita, ao mesmo tempo, manter a homeotermia interna e permitir que a temperatura da pele se aproxime com a do meio ambiente diminuindo a possibilidade de dissipação de calor, funcionando como isolante térmico.

O grau de isolamento varia individualmente, em geral na mulher é melhor; o obeso tem mais dificuldade de manter a temperatura normal no ambiente quente e o magro tem mais dificuldade de manter $o$ calor no organismo em ambiente frio.

\subsection{Regulação térmica da pele}

Esta regulação se processa por meio de transferência de calor para a pele, após condução pelos tecidos e pelo fluxo de sangue.

Os vasos sangüíneos penetram nos tecidos isolantes sub-cutâneos imediatamente abaixo da pele onde existe um plexo venoso de fluxo contínuo de sangue. Através dos mecanismos de vasoconstrição e vasodilatação, este plexo interfere na condução do calor por meio de um fluxo de sangue que pode variar de 0 a $30 \%$ do débito cardíaco total.

A partir da pele ocorre a transferência adicional de calor por radiação e evaporação, tornando-se a pele um sistema irradiador efetivo.

Quando a circulação está deprimida o corpo pedre calor por radiação e evaporação através do sistema isolador do corpo que, geralmente, é insuficiente para a adequada perda de calor, já que a perda por condução estará prejudicada.

A pele do homem é extremamente sensível à sua própria temperatura, podendo detectar alterações de até $0,01^{\circ} \mathrm{C}$ de temperatura cutânea média. No entanto, as sensações térmicas se adaptam rapidamente quando as alterações não são muito intensas.

\subsection{Secreção das glândulas sudoriparas}

A atividade secretora destas glândulas está sob o controle do sistema nervoso central através de inervação simpática. Sofrem influência também de situações emocionais, de exercícios e da temperatura local da pele.

Num indivíduo médio existem, aproximadamente, 2,5 milhões de glândulas sudoríparas que, ao excretarem o suor, expoliam o organismo de sódio, cloro, uréia, ácido lático e potássio quando a transpiração está aumentada. $\mathrm{O}$ aumento de $1^{\circ} \mathrm{C}$ na temperatura é suficiente para aumentar o estímulo da transpiração em 10 vezes, sendo este um dos principais mecanismos para reduzir a temperatura.

Normalmente, após temperatura cutânea de $36^{\circ} \mathrm{C}$ é que se inicia a sudorese. Um indivíduo normal tem a capacidade de suar 1,5 litro por 
hora, no máximo, em situações de extremo calor, fazendo com que ele perca, por dia 15 a $30 \mathrm{~g}$ de sal no mesmo período.

A medula espinhal humana isolada é incapaz de mediar respostas termorreguladoras eficientes, assim, nos casos de secção da medula espinhal, as respostas de sudorese ficam igualmente prejudicadas ${ }^{12}$.

\subsection{Aclimatação}

A aclimatação ao calor é um fenômeno muito importante na adaptação do indivíduo a temperaturas elevadas. Manifesta-se por uma tolerância corporal mais adequada, por meio de: aumento da sudorese, diminuição da concentração de sódio no suor e diminuição da frequiência cardíaca diante de um mesmo metabolismo de trabalho corporal. A sudorese e o calafrio alteram o ponto fixo da temperatura hipotalâmica para menos ou para mais, respectivamente, de modo que o organismo leva várias horas para alcançar um novo ajuste térmico, demonstrando o efeito desgastante dos episódios febris ou de temperaturas elevadas para o corpo. No caso de trabalhadores de áreas de alta temperatura a aclimatação demora de dias a meses para ocorrer, adaptando o organismo aos fenômenos citados e iniciando a sudorese com temperatura corporal de $33^{\circ} \mathrm{C}$ ao invés de $36^{\circ} \mathrm{C}$.

\subsection{Receptores termossensiveis e sensibilidade térmica}

Todos os tecidos biológicos são sensíveis à temperatura. Células do sistema nervoso com sensibilidade inusitadamente alta à temperatura são chamadas de receptores termossensíveis. Este sistema receptor para a deteç̧ão de variações térmicas fornece uma base para a re. gulação voluntária da temperatura orientando, por exemplo, a quanti. dade de roupa que se deve usar. Dois tipos de células receptoras encontram-se relacionadas à sensação térmica: corpúsculos de Krause, associados à discriminação de frio e os corpúsculos de Ruffini associados à sensação de calor. Um corpúsculo de Ruffini encontra-se frequientemente localizado junto a um plexo profundo de vasos.

Os receptores de temperatura, que parecem estar espalhados ao longo do corpo, detectam a temperatura e transmitem estas informações, através de vias neurais, ao hipotálamo. A maneira pela qual a integração dessas informações se processa é đesconhecida. Estes receptores existem na pele, nas vísceras profundas, na língua, no trato respiratório, na medula espinhal, na formação reticular mesencefálica, no hipotálamo e região pré-ótica do tronco cerebral, no bulbo e córtex motor.

Estudos sobre a capacidade de resposta a diversas dimensões de estímulos, revelam que há um número relativamente menor de pontos de resposta seletivos para a detecção de estímulos frios e táteis, comparado com a stimulação quente e dolorosa, embora existam mais receptores ao frio que receptores ao calor. A identificação periférica da 
temperatura relaciona-se principalmente com a detecção de temperaturas frescas e frias e não com a identificação de temperaturas quentes.

Os receptores de frio, especialmente na pele, são os principais responsáveis pela prevenção de temperaturas corporais baixas, estando em maior número na região do tórax e nos membros superiores.

A sensibilidade à temperatura muda de maneira não uniforme sobre a pele e mucosas, distríbuindo-se de maneira difusa na proporção de 4:1 até 10:1, respectivamente, de fibras aferentes de frio e de calor. Ambos os receptores (de frio e calor) são mais comuns na face e nas mãos. A testa é muito sensível ao frio mas relativamente insensível ao calor. Algumas regiões são completamente insensíveis ao calor.

\subsection{Sistema vasomotor}

$\mathrm{O}$ sangue, deixando o ventrículo esquerdo a aproximadamente $37^{\circ} \mathrm{C}$ é esfriado de $15^{5 \circ} \mathrm{C}$ à medida que progride em direção à mão, ou seja, transfere calor dos músculos e porções centrais do organismo para a pele. A temperatura interna se eleva proporcionalmente à intensidade do metabolismo, independentemente da temperatura externa, assim, 0 calor pode ser transferido contra gradiente térmico, através do sistema vasomotor. Para reduzir a temperatura corporal pode haver uma dila. tação interna dos vasos sanguíneos em até oito vezes.

\section{TEMPERATURA CORPORAL E PRATICA DE ENFERMAGEM}

Quais as implicações da medida da temperatura corporal para a prática de enfermagem? Estas dizem respeito a fatores que devem ser considerados quando o enfermeiro avalia o padrão individual de temperatura dos pacientes para determinar a frequiência da medida e as condutas pertinentes. Podem ser assim resumidos:

\subsection{Hospitalização e ambiente hospitalar}

Em primeiro lugar, a hospitalização em si mesma modifica o ritmo de vida do indivíduo e a doença e o "stress" poderão alterar o ritmo da temperatura corporal (ritmo circadiano).

Do mesmo modo, em algumas unidades como de recuperação anestésica, de terapia intensiva ou de exames e procedimentos especificos, deve-se acentuar as rotinas de verificação, com a finalidade de se detectar precocemente alterações significativas de temperatura e dos demais sinais vitais, que refletem o funcionamento dos sistemas que man. têm a homeostase, ou seja, do regulador da temperatura, do cárdio. respiratório e do regulador da pressão|

\subsection{Processos fisiopatológicos}

Há processos fisiopatológicos que exibem padrões específicos de alterações de temperatura como: infecções, doenças do sistema nervoso 
central, tumores, doenças hematológicas, embolia e trombose, interma. ção, distúrbios do equilíbrio hídrico, insuficiência cardíaca, doenças da tireóide, doenças hepáticas e gástricas, trauma tissular, anormalidades da pele, alergias, anestesias, sedação intensa e procedimentos cirúr. gicos.

Os extremos de temperatura interferem no metabolismo e na velocidade das reações bioquímicas do organismo. Os tecidos e sistemas do corpo humano funcionam melhor quando mantidos a um valor relativamente constante, próximo de $37^{\circ} \mathrm{C}$ (axilar), porque são sensíveis à temperatura. Afastamentos significativos deste valor, fora das variações habituais do indivíduo, estão relacionados com doença $\theta$ morte.

O modo como essas influências interferem na medida da temperatura deve ser conhecido pelo enfermeiro porque demanda diferentes interpretações para os resultados obtidos. Por exemplo, com relação ao meio ambiente, nas salas refrigeradas de uma recuperação anestésica com temperatura ambiente entre $21^{1}$ a $25^{5 \circ} \mathrm{C}$ os pacientes necessitarão de mais tempo para restabelecer sua temperatura ótima, do que aqueles que se mantiveram em locais com temperatura entre $26 \mathrm{e}$ $30^{\circ} \mathrm{C}{ }^{7,23}$.

A medida da temperatura deve estar sempre relacionada com a compreensão do fenômeno que está ocorrendo com o paciente, ou seja, no caso de uma hipertermia, esta pode ser consequiente a uma diminuição das perdas de calor pela pele ou pode ser resultante de um aumento da produção de calor pelo organismo, onde nas duas hipóteses, as ações de enfermagem são diferentes para cuidar do paciente.

Quando se trata especificamente da entidade nosológico febre, existem fases bem características do processo febril que desencadeiam sinais e sintomas distintos em cada fase, onde o cuidado de enfermagem demanda ações igualmente distintas, que, se confundidas, podem cau. sar efeitos reacionários que elevam a temperatura ainda mais.

\subsection{Administração de medicamentos e processos invasivos}

Cabe ressaltar as alterações de temperatura relacionadas à administração de medicamentos, soros, sangues e à introdução de catéteres vários (intra-venosos, sonda vesical), que dizem respeito diretamente à prática de enfermagem.

$\mathrm{Na}$ administração de medicamentos, as ligações droga-receptor dissociam-se reversivelmente à temperatura corporal. Portanto, pequenas mudanças podem resultar numa perda ou redução marcante da atividade específica da dose ministrada, conforme os diferentes indices terapêuticos das classes de drogas.

\subsection{Procedimentos}

As medidas de temperatura sofrem limitações do local de colocação do termômetro ( $\mathrm{T}$. oral, axilar ou retal), da técnica de medida 
(tempo de exposição suficiente, posição do instrumento, fabricante e peculiaridades anatomofisiológicas do local), das especificidades circadianas do cliente febril e afebril e do meio ambiente.

\subsection{Problemática da medida da temperatura corporal}

O problema da medida ou verificação da temperatura corporal refere-se a incorporação deste procedimento, juntamente com a medida dos sinais vitais, como rotina, geralmente delegada ao pessoal auxiliar de enfermagem. Não há preocupação com a adequação dos horários de medida, com a qualidade da execução do procedimento e, principalmente, com a interpretação dos valores obtidos. As rotinas de verificação são fundamentadas na tradição empírica e na conveniência para a equipe de enfermagem, não em pesquisas $3,6,15,16,19$.

Existe discordância tanto quanto aos limites de normalidade para as temperaturas como na interpretação dos valores obtidos. $\mathbf{A}$ indicação médica para os antitérmicos também não é uniforme, havendo prescrições para temperaturas a partir de $37^{5 \circ} \mathrm{C}$ a serem ministradas em qualquer período do dia.

Do mesmo modo não há indicação precisa dos locais do corpo a serem utilizados para as medidas da temperatura pois os limites de valores também variam conforme a literatura $2,6,8,12,13,24,25$. Deste modo encontra-se que a temperatura axilar varia de $37^{2}$ a $37^{40} \mathrm{C}$, a temperatura oral varia de $37^{8}$ a $38^{\circ} \mathrm{C}$ e a temperatura retal de $38^{4}$ a $38^{6 \circ} \mathrm{C}$, conside-

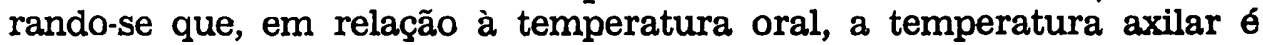
$0,6^{\circ} \mathrm{C}$ mais baixa e a temperatura retal, $0,6^{\circ} \mathrm{C}$ mais alta.

Outro aspecto é o da operacionalização dos controles de sinais vitais: quem mede estes valores são, habitualmente, atendentes, seguidos dos auxiliares de enfermagem. Observa-se que nem sempre os funcionários obedecem os tempos corretos de exposição do termômetro. Além disso, à tarde e à noite, nem sempre há número suficiente de funcionários que permita mensurações dos pacientes que as necessitam. Os valores vespertinos são importantes pois as hipertermias são mais freqüentes no período da tarde ${ }^{3,25}$.

Os gráficos de temperatura trazem impressos horários padroniza. dos $(8 \mathrm{~h}-12 \mathrm{~h}-16 \mathrm{~h}-20 \mathrm{~h})$, cujas anotações nem sempre corres. pondem ao horário de mensuração. Assim, medidas efetuadas no período da "manhã" normalmente correspondem, no gráfico, ao horário das 8 horas. A temperatura corporal é variável em relação ao horário de medida. Portanto, é preciso que o enfermeiro reflita sobre estes aspectos ao avaliar a oportunidade com que decide por uma ou outra conduta acerca das medidas da temperatura corporal de seus pacientes.

\subsection{Resultados práticos das pesquisas realizadas por enfermeiros rela. cionadas à medida da temperatura corporal $3,4,6,24,25$}

As pesquisas relacionadas com a medida da temperatura corporal, entre outras conclusões importantes revelam que: 
- as medidas das temperaturas axilar, oral e retal são estatisticamente mais elevadas nos pacientes femininos em relação aos masculinos;

- a temperatura corporal medida na axila revela os menores valores, comparada às medidas na boca e no reto, de acordo com o sexo e o período de mensuração;

- a temperatura ambiente e umidade relativa do ar não têm efeito estatisticamente significativo na medida das temperaturas axilar, oral e retal;

- as menores diferenças entre as temperaturas estão entre as médias das temperaturas oral e retal e as maiores diferenças, entre as médias das temperaturas axilar e retal;

- a temperatura corporal apresenta um ritmo de 24 horas, com valores mais baixos pela manhã, elevação à tarde e queda pela madrugada;

- há diferença nos valores de temperatura entre indivíduos e no mesmo indivíduo, que não se repetem da mesma forma;

- a temperatura corporal é variável em relação ao horário de medida. Só ocasionalmente a medida tomada em um horário será igual à anterior ou subsequiente;

- o termômetro eletrônico fornece valores sistematicamente superiores ao termômetro clínico na região retal, enquanto que nas regiões oral e axilar apresentam-se superiores aos termômetros clínicos em somente metade dos casos. Portanto a utilização do termômetro eletrônico é tão passível de interferências como o termômetro clí. nico.

\section{CONCLUSŐES}

- a fisiologia da temperatura corporal envolve vários mecanismos: controle fisiológico (neurológico) e comportamental, equilíbrio entre produção e perda de calor, sistema isolador do corpo, regulação térmica da pele, secreção das glândulas sudoríparas, aclimatação, receptores termossensíveis e sensibilidade térmica, sistema vasomotor;

- os mecanismos de regulação da temperatura corporal sofrem influência de: idade, exercícios e atividade muscular, hormônios, ritmo circadiano, ambiente, sexo, emoção, alimentos, líquidos e fumo, sono, doenças e natureza da febre, medicamentos, postura corporal e "stress";

- - febre e hipertermia maligna são entidades nosológicas com caracte- :rísticas bem definidas, que orientam o planejamento da assistência;

- os conceitos relativos à temperatura e suas alterações devem ser bem definidos porque demandam interpretações distintas para o planejamento da assistência; 
- a medida da temperatura corporal envolve conhecimentos da problemática da execução do procedimento e das implicações para a prática de enfermagem, no sentido de melhorar a determinação de rotinas de fato necessárias, conforme o tipo de paciente.

LAGANÁ, M.T.C.; FARO, A.C.M. e; ARAUJO, T.L. Body temperature as a nursing problem: concepts and regulative mechanisms. Rev. Esc. Enf USP, v. 26, n.2, p. 173-86, Aug. 1992.

The present study showes the body temperature regulation mechanisms, the conceptions related to the temperature and their alterations and describes pyrexia and malignant hyperthermia phenomena.

UNITERMS: Body temperature. Fever. Nursing care. Regulation.

\section{REFERENCIAS BIBLIOGRAFICAS}

1. ALMEIDA NETO, M.A. et al. Hipertemia maligna: relato de dois casos. Rev. Braa. Anest., v. 35, n. 3, p. 191-3, 1985.

2. ANGERAMI, E.L.S. Estudo da temperatura corporal, medida na axila, para estabelecer limites de classificação do normal, em colegiais do sexo feminino. Rov. Bras. Ent., v. 24, n. $1 / 2$, p. $17-26,1971$.

3. Hotina de verificacão de temperatura: Estudo de alguns fatores interferentes $\theta$ suas implicações. Ribeirão Preto, 1972. 92 p. Tese (Doutorado) - Escola de Enfermagem de Ribeirão Preto, Universidade de São Paulo.

4. ANGERAMI, E.L.S.; PEDRAZZANI, J.C. Tecnologia em enfermagem: mensuração da tem. peratura corporal (axilar) com termômetro eletrónico. Rev. Paul. Hosp., v. 27, n. 2, p. 214-9, 1974.

5. ATKINS, E. Febre. In: McBRYDE, C.M.; BLCKLOW, R.S. Sindis e sintomas. 5 ed. Rio de Jianeiro, Guanabara Koogan, 1975, Cap. 25, p. 431-49.

6. CINTRA, F.A. Estudo das relusões entre as temperaturas oral, axilar e retal, em pacientes clínicos internudos em hospital-escola. Ribeirão Preto, 1987. 108 p. Dissertação (Mestrado) - Escola de Enfermagem de Ribeirăo Preto, Universidade de Săo Paulo.

7. CUNHA, A.M. et al. Análise da rotina de verificação dos sinais vitais dos pacientes noo pós-operatório imediato, em um centro ae recuperação anestésica. Ent. Nova Dimens. v. 3 , n. 2, p. $114-20,1977$.

8. DUGAS, B.W. Enfermagem prática. 1 ed. Rio de Janeiro. Interamericana, 1984.

9. GANONG, W.F. Fisiologia médica. 4 ed. Såo Paulo, Atheneu, 1983. p. 191-5: Regulaçåo da temperatura.

10. Fisiologia médica. 4 ed. São Paulo, Atheneu, 1983. p. 84-8: Sensibilidade cutanea, profunda e visceral.

11. GUYTON, A. Tratado de fisiologia médica. 6 ed. Rio de Janeiro, Interamericana, 1984. Cap. 50, p. 530-42: Sensacōes somáticas: dor, dor visceral, cefaléia e sensacões térmicas.

12. Tratado de fisiologia médica. 6 ed. Rio de Janeiro, Interamericana, 1984. Cap. 72 ๖. 765-75: Temperatura corporal, regulação da temperatura $\theta$ febre.

13 HARRDY, J.D.; BARD, P. Regulação da temperatura corpórea. In: MOUNTCASTLE, V.B. Fisiologia médica. 13 ed. Rio de Janeiro, Guanabara Koogan, 1978. Cap. 56, p. $1306-42$.

14. JOAQUIM, E.H.G. Hipertermia maligna: diagnóstico precoce com capnografia de gás expirado - diferentes quadros clinicos no mesmo paciente - (relato de caso). Rev. Bras. Anest., v. 39, p. 20, 1989. Suplemento 11. 
15. MACHADO, M.H. et al. Reavaliaça de rotinas em enfermagem - análise da importancia clínica da verificação da frequiência respiratória em pacientes hospitalizados. Enf. Novas Uimens. v. 1, n. 5, p. 248-52, 1975.

16. MACHADO, M.H.; NETTO, R.A. Variaça dos resultados na verificação dupla-cega de frequêencia cardiaca, frequêencia de pulso e frequência respiratória. Lnf. Nova Dimens. v. 1 , n. 2 , p. $75-80,1975$.

17. McBRYDE, CM., BLACKLOW, R.S. Sinais e sintomas. 5 ed. Rio de Janeiro. Guanabara Koogan, 1975.

18. MENDES, F.F. et al. Hipertermia maligna durante cirurgia ortopédica: relaiu de un caso. Rev. Bras. Anest., v. 39, n. 3, p. 203-6, 1989.

19. MOORAT, D.S. The cost of taking temperatures. Nurs. Times, v. 72, n. 20, p. 767-70, 1976.

20. MOUNTCASTLE, V.B. Fisiologia médica. 13 ed. Rio de Janeiru, Guanabara Koogan, 1978, p. 375-8: Sensibilidade à dor e temperatura.

21. PAYMAN, B.C. et al. Postoperative temperature and infection in patients underguing general surgery. J. Adv. Nurs., v. 14, n. 3, p. 198-202, 1989.

22. PERfira, H.G. et al. Patogenia da febre e tratamento antitérmicu: a febre em atelldimento de emergência. ARS CURANDI, v. 19, 11. 4, p. 68-81, 1986.

23. SALZANO, S.D.T. Eetudo da variạão de temperatura corpórea no paciente anestésicocirúrgico. São Paulo, 1972. 53 p. Tése (Dututorado) - Escula de Enfermagenı, Universidade de São Paulo.

24. SAPORITI, E.L. et al. Vuriacôes nus resultadus da niensuração da temperatura corporal. Enf. Atuad, v. 5, n. 26, p. 4-7, 1982.

25. TERRESI, R.M.N. Estudo das relaçōes entre as temperaturas oral, uxilar e retal, em adultos jovens do sexo feminino. Ribeirão Preto, 1988, 84 p. Dissertação (Mestrado) Escola de Enfermagem de Ribeirão Preto, Universidade de São Paulo. 